\title{
Physiochemical and Phase behaviour study of Jatropha curcus oil - ethanol microemulsion fuels using sorbitane fatty esters
}

\author{
Vivek Patidar ${ }^{1}$, Abhishek Chandra ${ }^{1}$, Man Singh ${ }^{1, ~}{ }^{*}$, Raosaheb Kathalupant Kale ${ }^{1,2}$ \\ ${ }^{1}$ School of Chemical Science, Central University of Gujarat, Gandhinagar-382030, India \\ ${ }^{2}$ School of Life Sciences, Jawaharlal Nehru University, New Delhi-110067, India
}

Email address:

vivekcug@yahoo.com (V. Patidar), abhishekchandra.15@gmail.com (A. Chandra),mansingh50@hotmail.com (M. Singh), raosahebkale@gmail.com (R. K. Kale)

\section{To cite this article:}

Vivek Patidar, Abhishek Chandra, Man Singh, Raosaheb Kathalupant Kale. Physiochemical and Phase Behaviour Study of Jatropha curcus Oil - Ethanol Microemulsion Fuels Using Sorbitane Fatty Esters. International Journal of Renewable and Sustainable Energy. Vol. 3, No. 1, 2014, pp. 13-19. doi: 10.11648/j.ijrse.20140301.13

\begin{abstract}
Vegetable oil reverse micelle microemulsions have been an alternative method of biodiesel production to eliminate and avoid transesterification as well as unpurified glycerol. Sorbitane fatty ester surfactants due to their high solubilization capacity forms microemulsions with oils and thus span based reverse micelle microemulsion systems have been studied. Jatropha oil-ethanol microemulsions have been prepared using span 80 and 85 surfactants and optimized as biofuel, their phase behavior with physicochemical parameters: density, viscosity and surface tension were analyzed for formulation. The surface tension has been an important physicochemical parameter in addition to kinematic viscosity elucidating Jatropha oil-ethanol microemulsion with span 80 than with span 85, as a better biofuel. Comparatively, a lower amount of span 80 than span 85 was utilized for microemulsion formulations and resulted viscosities were in close agreement with ASTM biodiesel standards. The microemulsification approach has been found a sustainable method for producing biofuels without chemical reactions and their fuel properties have been adjusted through variable formulations.
\end{abstract}

Keywords: Microemulsion, Phase Behavior, Biofuel, Kinematic Viscosity, Surface Tension

\section{Introduction}

Presently, with the increasing impact of environmental pollution due to increase in exhaust emissions and depletion of petroleum reserves, there is a burning need to develop alternative energy resources, such as biofuel which is greener and environment friendly. On account of several advantages such as renewable and non-toxic nature, vegetable oils are being considered as an alternative fuel source. Therefore, vegetable oils have emerged as an alternative renewable source of green fuels globally [1-3]. Vegetable oils such as soybean, peanut, sunflower, rape, coconut, karanj, neem, cotton, mustard, jatropha, linseed and caster have shown a performance quite comparable to diesel fuels [4-7].

Vegetable oil as engine fuel is not a new concept because the inventor of diesel engine, Rudolph Diesel ran his diesel engine on peanut oil as the fuel [8]. Vegetable oils contain triglycerides as a primary component producing high viscosity. Due to the high viscosity, long term use of neat vegetable oils affects the engine durability resulting in injector coking and ring sticking [9, 10]. Additionally, the vegetable oils have higher cloud and pour points considered as unfavorable parameters in cold weather conditions [11]. So several methodologies have been applied to overcome these difficulties for preparing biofuel such as dilution method where vegetable oils in small portions are blended with diesel; microemulsion (ME) method where oils are mixed with alcohols using surfactants; pyrolysis by simple cracking of vegetable oils either by heating directly or with catalysts, a less energy efficient method and lastly transesterification comprising a reversible chemical reaction between oil and short chain alcohols producing biodiesel and glycerol with catalysts [12-15]. The biofuel obtained through these methods are biodegradable and environmentally friendly however their high cost, poor cold flow properties and increasing nitrogen oxides $\left(\mathrm{NO}_{\mathrm{x}}\right)$ in exhaust emissions have been few of the disadvantages [16-18]. 
Transesterification is widely applied for reducing viscosity of oils and obtained biodiesel has kinematic viscosity, specific gravity, cetane number and gross heat of combustion as compared to No. 2 diesel. In transesterification reaction, the triglycerides react with alcohols in the presence of catalysts producing glycerol as a byproduct with biodiesel. Purification or conversion of glycerol into a value added product is an expensive process and its disposal causes environmental pollution [19, 20]. Therefore, biodiesel preparation by microemulsification of oils could be applied to prevent formation of glycerol. The biofuels obtained from this method are transparent and thermodynamically stable, reported as Winsor Type II microemulsions where the polar ethanol phase is dispersed in non-polar phase due to reverse micelle formation [21-24]. The fact that Jatropha curcus oil (JCO) cannot be used for dietary purposes without detoxification that makes it a very attractive feedstock for biodiesel. Earlier studies have shown that JCO based biodiesel has similar properties to that of petroleum-based diesel [25]. In view of all these facts, JCO and ethanol were chosen as renewable energy sources for ME preparation with spans where, JCO is an extract of jatropha curcus plant and ethanol is the fermentation product of sugarcane and corn while spans 80 (sorbitane monooleate) and span 85 (sorbitane trioleate) are bio-compatible surfactants. Mixing oil with alcohols is one of the approaches to achieve standard biodiesel viscosity alongside other physicochemical properties (PCP): density and surface tension are essential indicators for proper analysis of biodiesel. For instance, the cetane number and

(a)

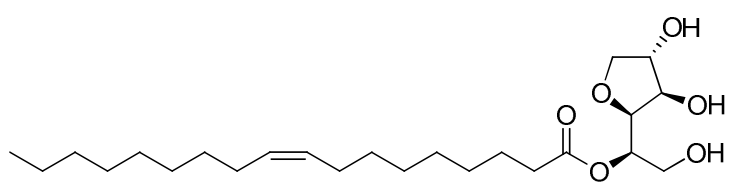

Figure 1. Structure of non-ionic surfactants: (a) span 80, (b) span 85.

Table 1. Fatty acid profile of JCO

\begin{tabular}{ll}
\hline Fatty acid & \% Composition $^{\mathbf{a}}$ \\
\hline Palmitic (C16:0) & 13.48 \\
Stearic (C18:0) & 7.25 \\
Oleic (C18:1) & 42.25 \\
Linoleic (C18:2) & 36.56 \\
Arachidic (C20:0) & 0.18 \\
Behenic (C22:0) & 0.13 \\
\hline
\end{tabular}

a analyzed by gas chromatography (GC) with flame ionization detector (FID) gross heating values are directly related to density and affect fuel efficiency [26-28]. Similarly, viscosity is an important parameter for development of fuels that governs the engine operation [29-30]. Surface tension is one of the vital PCP that directly affects fuel atomization due to cohesive forces and hence the biodiesel with higher surface tension values hamper the correct fuel atomization on an engine combustion chamber due to difficulty in small fuel droplet formation [31]. Despite such an important role in fuel combustion, there is only a limited literature reported on surface tension. Therefore, our work reports experimental density, viscosity and surface tension of span based JCO microemulsions (MEs) in a wide temperature range of $T=(298.15,303.15,308.15$ and 313.15$) \mathrm{K}$ and ambient pressure to bring them to a usable form.

\section{Materials and Methods}

\subsection{Materials}

Non-edible grade JCO was acquired from Agarwal oils (Udaipur, Rajasthan, India) and its chemical composition was analyzed by gas chromatography (GC) with flame ionization detector, given in Table 1. JCO has shown iodine and acid values as $102 \mathrm{~g} / 100 \mathrm{~g}$ and $2.8 \mathrm{mg} \mathrm{KOH} / \mathrm{g}$, respectively. Ethanol ( $\geq 99.8 \%$ ), span 80 (HLB number 4.3 ) and span 85 (HLB number 1.8) were used as received from Sigma-Aldrich, span molecular structures are depicted in Fig. 1.

(b)

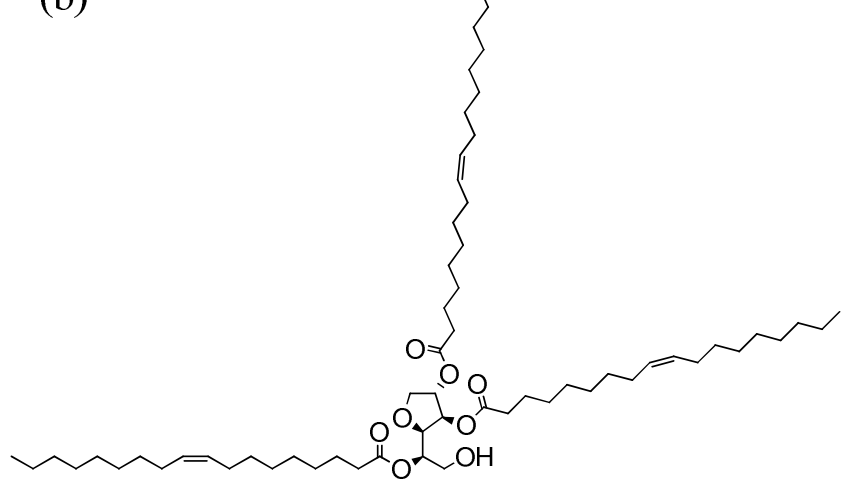

\subsection{Methods}

\subsubsection{Microemulsion Preparation}

Binary mixtures of ethanol and JCO from 0 - $100 \%$ (w/w) were prepared with an accuracy of $\pm 0.0001 \mathrm{~g}$ using Mettler Toledo New Classic MS with continuous stirring at 500 RPM. Solutions up to $20 \%$ were transparent while above which were cloudy. For 20 - $90 \%$ JCO-ethanol binary mixtures, the variable amounts of span were added to formulate stable and transparent MEs. Solutions above $90 \%$ were clear without span addition. JCO-ethanol and JCO-ethanol-span mixtures were continuously stirred at 500 
RPM and their thermodynamic stability was checked from 298.15 to $313.15 \mathrm{~K}$ using a thermal water bath.

\subsubsection{Ternary Phase Diagram}

For the study of phase behavior and stability of MEs, ternary phase diagram was used where the three vertices of the equilateral triangle represent the three components of ME [17]. The two vertices at the bottom depict weight percent of JCO at left side and ethanol at right, while the upper vertex represents span. The composition at each point in diagram demonstrates weight percent of three components A, B, C as under [30].

$$
x \% A+y \% B+z \% C=100 \%
$$

Miscibility curve is plotted between two liquid phases and single phase MEs of Oil-Ethanol-Span. The region above the curve is a single phase transparent and thermodynamically stable MEs with minimum surfactant. The two immiscible phases appear below the curve, and found to be similar as Winsor Type II $[32,33]$.

\subsubsection{Density, Viscosity and Surface Tension Measurements}

Density ( $\rho)$ of pure components and mixtures were measured using Anton Paar DSA 5000M densimeter whose temperature was controlled to $\pm 0.001 \mathrm{~K}$ built-in Peltier device. Sensitivity of the instrument corresponds to $\pm 5 \cdot 10^{-3}$ $\mathrm{kg} \cdot \mathrm{m}^{-3}$ precision. The densimeter was calibrated with Millipore water and reported densities are an average of three consecutive measurements. Viscosity and surface tension measurements were done with Borosil Mansingh Survismeter (Cal.no. 06070582/1.01/ C-0395, NPL, India) by flow time and pendant drop methods controlled by Lauda Alpha KA 8 thermostat with $\pm 0.01 \mathrm{~K}$ control [34-37]. The survismeter was calibrated with ethanol and water, and compared with literature values [38-40]. Viscosity and surface tension are an average of three consecutive measurements with $\pm 0.0001 \mathrm{~mm}^{2} \cdot \mathrm{s}^{-1}$ and $\pm 0.03 \mathrm{mN} \cdot \mathrm{m}^{-1}$ uncertainties respectively.

\section{Results and Discussion}

\subsection{Phase Behavior}

Figs. 2 and 3 depict the miscibility curves of prepared MEs, and show a critical role of linear and branched structures of span 80 and 85 respectively with JCO-Ethanol at $298.15 \mathrm{~K}$. The results distinguished the surfactants attributing maximum solublisation of ethanol in the oil phase. For example, 51, 45, 27, 14 and $2 \%$ less amount of span 85 was required than span 80 for $25,30,35,40$ and $45 \%$ ethanol in JCO, respectively whereas for $50,55,60$, $65,70,75,80,85$ and $90 \%$ ethanol in JCO; 7, 19, 19, 28, $31,34,39,52$ and $69 \%$ less span 80 was required than span 85 (Figs. 2 and 3). The span 80 contains three $\mathrm{OH}$ groups with a straight oleate chain and span 85 contains one $\mathrm{OH}$ group with branched trioleate chain (Fig.1), have increased the oil and ethanol solubility respectively. Thus, it has proven that the branching and number of $\mathrm{OH}$ groups affected the hydrophobicity and hydrophilicity of MEs system respectively. It is also evident that the oils containing triglycerides are highly hydrophobic with longer and bulkier alkyl chains of triglycerides [41, 42], and thus, the span 80 is identified as the potential surfactant to achieve a single phase ME with less amount.

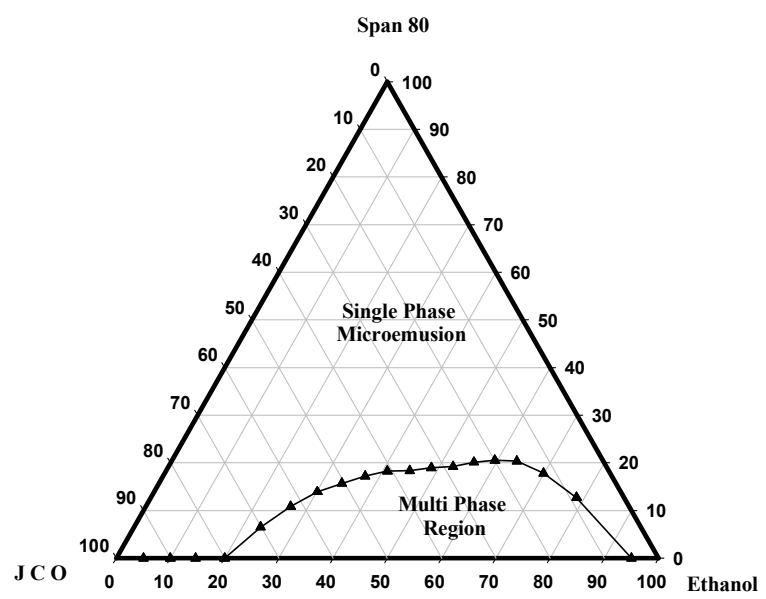

Figure 2. Ternary phase diagram of JCO-ethanol-span 80 system at room temperature

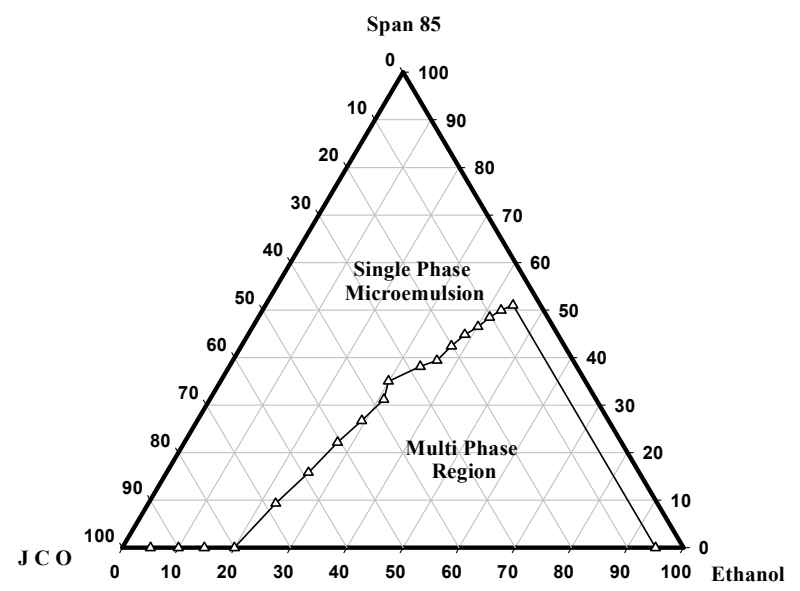

Figure 3. Ternary phase diagram of JCO-ethanol-span 85 system at room temperature.

\subsection{Physicochemical Study}

\subsubsection{Density, Kinematic Viscosity and Surface Tension}

The effect of increasing ethanol concentration on density of the miscible systems from $\mathrm{T}=(298.15$ to 313.15$) \mathrm{K}$, illustrated in Figs. 4 and 5. The density has decreased with increase in ethanol concentration where with span 80 , between $25-90 \%$ ethanol, the rate of decrease in density is $0.52 \%$ while with span 85 is $0.11 \%$.From $90 \%$ onwards without span, the density decreased sharply. It seems that on addition of ethanol up to $20 \%$, the strongest hydrophobic-hydrophobic interactions $\left(\mathrm{H}_{\mathrm{b}} \mathrm{H}_{\mathrm{b}} \mathrm{I}\right)$ within oil molecules have weakened due to the development of 
hydrophilic-hydrophilic interactions (HHI) between oil and ethanol and caused a decrease in density. The higher rate of decrease in density with span 80 might be due to a dominance of weaker HHI between ethanol-span over stronger $\mathrm{H}_{\mathrm{b}} \mathrm{H}_{\mathrm{b}} \mathrm{I}$ between oil-oil and weaker $\mathrm{HbHbI}$ between span-oil. These interactions have developed due to the presence of one oleate chain in span 80 and 3:1 ratio of $\mathrm{OH}$ in span 80 and ethanol. With span 85 , the lower rate of decrease in density might be due to increase in $\mathrm{H}_{\mathrm{b}} \mathrm{H}_{\mathrm{b}} \mathrm{I}$ which increased the hydrophobicity induced by trioleate chain of span 85, as well as decrease in HHI because of 1:1 ratio of $\mathrm{OH}$ in span 85 and ethanol. From $80 \%$ onwards, hydrophobicity decreased due to decrease in oil and span concentrations which developed stronger HHI due to increase in ethanol concentration that caused a sharp decrease in density. MEs with span 85 have higher densities than span 80 because span 85 with three oleate branching developed stronger $\mathrm{H}_{b} \mathrm{H}_{b} \mathrm{I}$ between oil and span 85 .

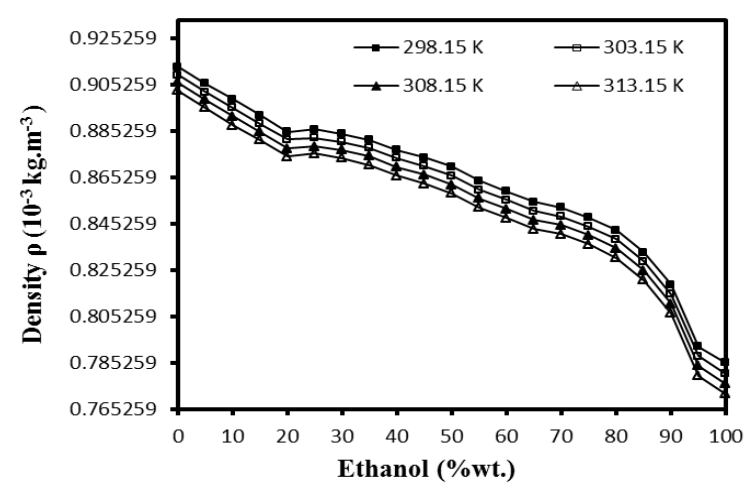

Figure 4. Densities of JCO-ethanol microemulsions with span 80

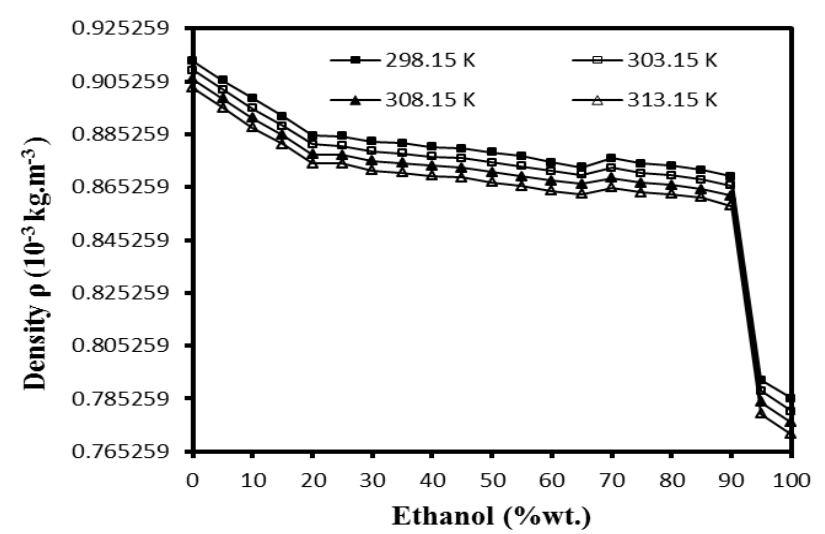

Figure 5. Densities of JCO-ethanol microemulsions with span 85

Kinematic viscosities are illustrated in Figs. 6 and 7, which decreased with increase in ethanol concentration. Initially, up to $20 \%$ ethanol addition, the kinematic viscosity has decreased sharply within $5-12 \mathrm{~mm}^{2} . \mathrm{s}^{-1}$ and after $20 \%$ onwards with span 80 , the same decreased steadily within $0.7-2.3 \mathrm{~mm}^{2}$. $\mathrm{s}^{-1}$. Initially at zero ethanol concentration, only strong $\mathrm{H}_{b} \mathrm{H}_{b} \mathrm{I}$ prevailed within the oil system. When the concentration of ethanol was increased, the stronger $\mathrm{H}_{b} \mathrm{H}_{b} \mathrm{I}$ were weakened with development of weaker $\mathrm{H}_{b} \mathrm{H}_{b} \mathrm{I}$ between a larger hydrophobic group of oil and smaller ethyl chain of ethanol. Above $20 \%$ ethanol, a dominance of HHI between ethanol-ethanol resulted in phase separation of oil and ethanol. To mutually solubilize the two phases, span was added carrying with hydrophobic domain and polar $\mathrm{OH}$ group. The span mutually solubilized the components, and a stable ME were obtained where a very less impact of ethanol concentration on kinematic viscosity was observed due to the counterbalance between $\mathrm{HbHbI}$ and $\mathrm{HHI}$ induced by span 80 (Figs. 6). When span 85 was added, the counter balancing effect between the $\mathrm{H}_{\mathrm{b}} \mathrm{H}_{\mathrm{b}} \mathrm{I}$ and $\mathrm{HHI}$ was less than with span 80 due to presence of trioleate chain which increased the $\mathrm{H}_{b} \mathrm{H}_{b} \mathrm{I}$, and as a result the kinematic viscosities are on the higher end as shown in Fig. 7. The kinematic viscosity of MEs with span 80 at $313.15 \mathrm{~K}$ with ethanol-oil ratios 55:45, 60:40, 65:35, 70:30, 75:25, 80:20, 85:15 and 90:10 have found similar to biodiesel, B100 (1.9-6 $\left.\mathrm{mm}^{2} \mathrm{~s}^{-1}\right)$, and in closest agreement with the standard of ASTM D6751-02 [43]. Thus, with phase behavior, density and kinematic viscosity studies have proven that the span 80 based MEs have a most favorable path for making biofuel.

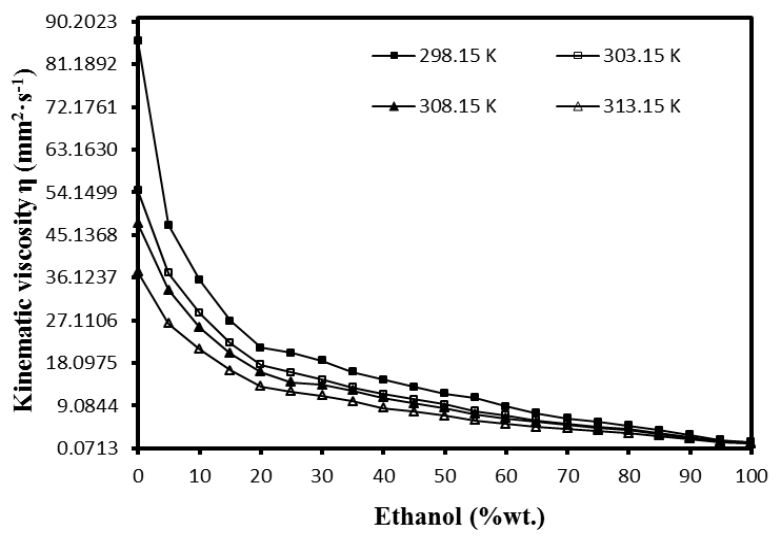

Figure 6. Viscosities of JCO-ethanol microemulsions with span 80

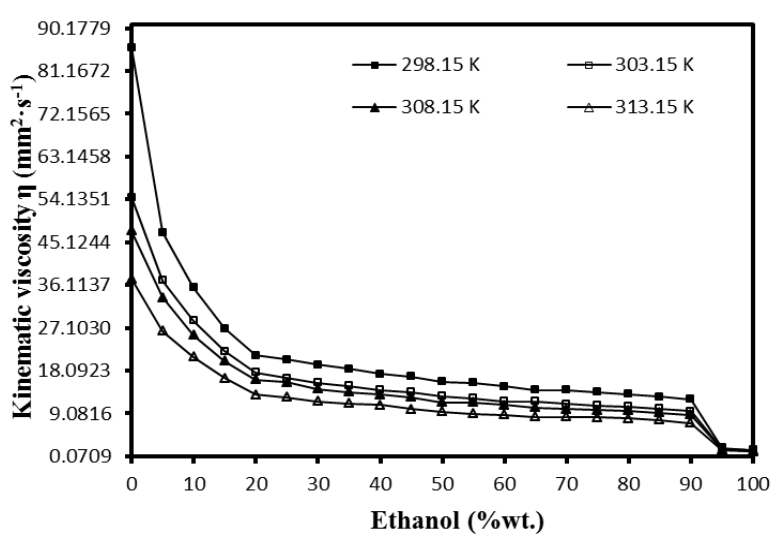

Figure 7. Viscosities of JCO-ethanol microemulsions with span 85

Surface tensions of MEs have decreased with an increase in ethanol concentration as illustrated in Figs. 8 and 9. It seems that initially up to $20 \%$ ethanol concentration, the surface tension decreased sharply, and $20 \%$ onwards with span 80 , increased at the rate of $0.04 \mathrm{mN} \cdot \mathrm{m}^{-1}$ with per $\%$ 
increase in ethanol concentration at $293.15 \mathrm{~K}$. The sharp decrease in surface tension might be due to a weakening of strong cohesive forces in the form of $\mathrm{H}_{b} \mathrm{H}_{b} \mathrm{I}$ existing in oil and development of weaker $\mathrm{H}_{b} \mathrm{H}_{b} \mathrm{I}$ between oil-ethanol. The systematic representation of $\mathrm{H}_{\mathrm{b}} \mathrm{H}_{\mathrm{b}} \mathrm{I}$ and $\mathrm{HHI}$ between oil, ethanol and surfactant is illustrated through JCO ethanol interaction model, Fig.10. After the addition of span 80 and with increasing ethanol concentration, development of stronger HHI between span and ethanol caused a constant increase in surface tension. With span 80 , after $80 \%$ ethanol, the surface tension has decreased sharply due to diminishing stronger $\mathrm{H}_{\mathrm{b}} \mathrm{H}_{\mathrm{b}} \mathrm{I}$ of oil-oil and developing $\mathrm{HHI}$ of ethanol-ethanol. With span 85, after $20 \%$ onwards, at $298.15 \mathrm{~K}$, the surface tension has increased with the rate of $0.004 \mathrm{mN} . \mathrm{m}^{-1}$ while at $303.15,308.15$ and $313.15 \mathrm{~K}$, decreased with the rate of $0.007,0.003$ and 0.008 respectively. This reverse trend in surface tension with temperature indicates the thermal behavior of MEs. The rate of increase or decrease in surface tension between $25-80 \%$ with span 85 is lower than span 80 because increasing HHI of span 85-ethanol and ethanol-ethanol was compensated by $\mathrm{H}_{b} \mathrm{H}_{\mathrm{b}} \mathrm{I}$ of oil-span 85 due to the trioleate chain. The surface tension with span 80 was more than with span 85 because span 80 with three $\mathrm{OH}$ groups developed stronger HHI with ethanol. Thus, the three $\mathrm{OH}$ groups of span 80 increased the surface forces and produced higher surface tension than span 85.

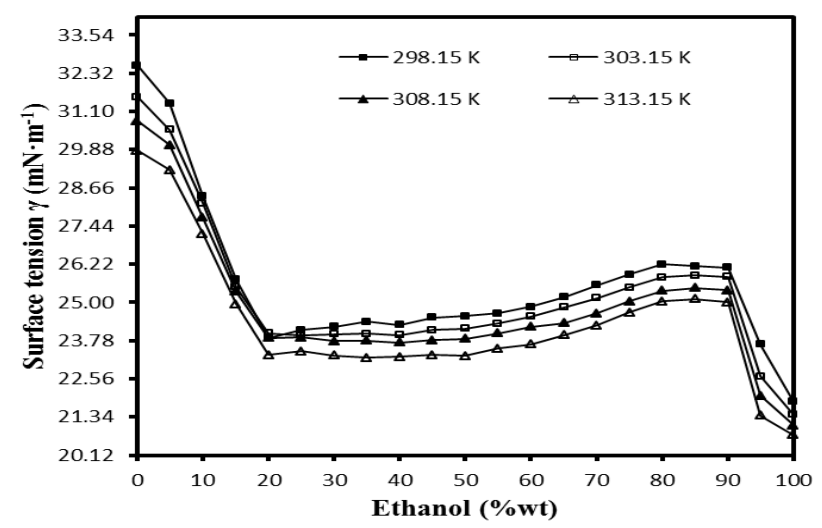

Figure 8. Surface tensions of JCO-ethanol microemulsions with span 80

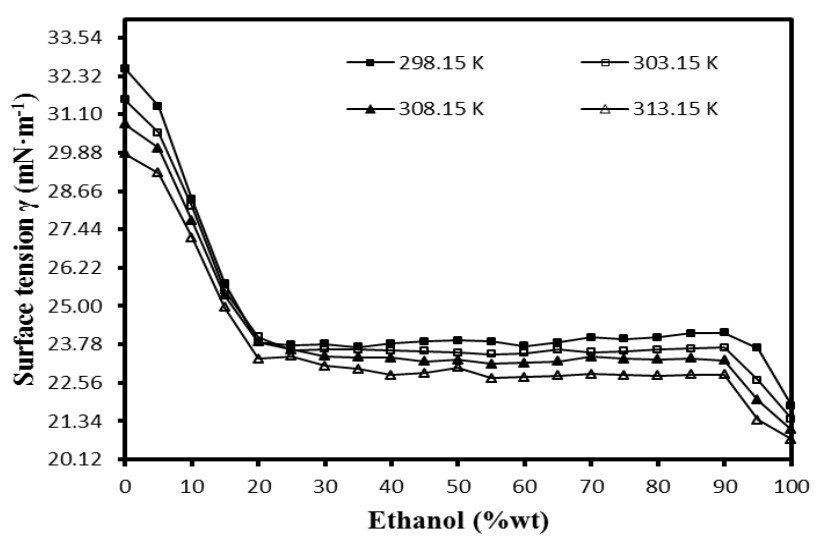

Figure 9. Surface tensions of JCO-ethanol microemulsions with span 85

\section{Conclusions}

This study has elucidated the physicochemical characterization of span based Jatropha oil-ethanol MEs to be used as biofuel. Unlike sulfate-based extended surfactants, ME fuel of spans are an environmentally desirable fuel; since there is no sulfur content in span preventing sulfur oxide $\left(\mathrm{SO}_{\mathrm{x}}\right)$ emissions. Also the MEs were stable without any phase separation up to $313.15 \mathrm{~K}$. From the phase behavior, density, viscosity and surface tension studies, the optimum system found is the system of span 80 based JCO-ethanol MEs. This fuel system is stable in a temperature range of 298.15-313.15 $\mathrm{K}$ and the optimum system for this study is span 80 based JCO-ethanol MEs. The 55:45,60:40, 65:35, 70:30, 75:25, $80: 20,85: 15$ and 90:10 ratios of ethanol : oil with span 80 have kinematic viscosity meeting the ASTM standard of B100 biodiesel $\left(1.9-6 \mathrm{~mm}^{2} \mathrm{~s}^{-1}\right)$ at $313.15 \mathrm{~K}$. These newly developed JCO-ethanol-span 80 MEs could be used as renewable and eco-friendly fuels with high calorific values on designing surfactant based biofuel.

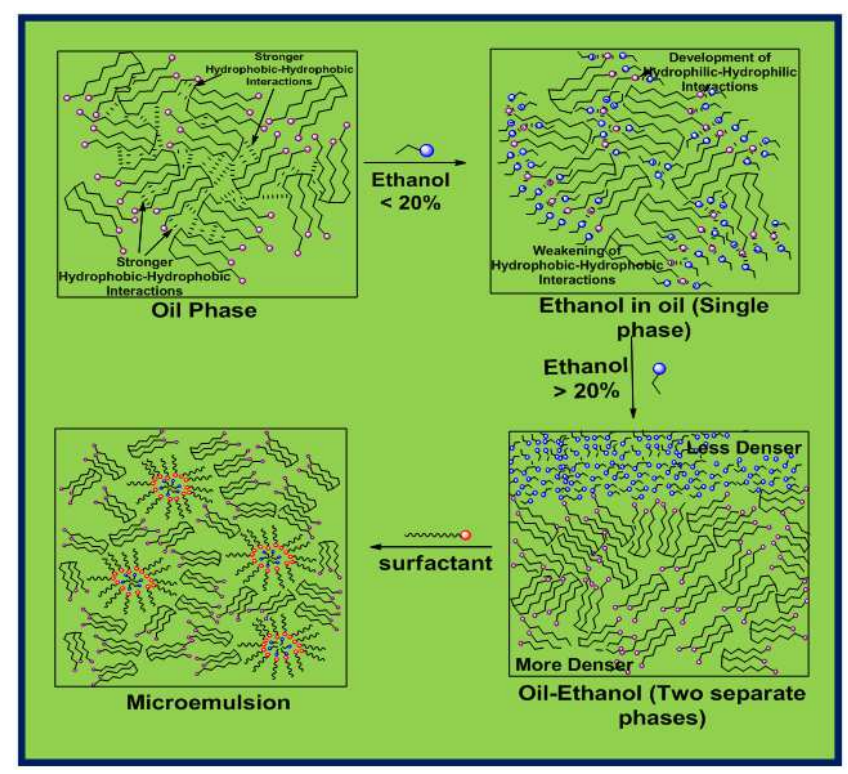

Figure 10. JCO Ethanol interaction model

\section{Acknowledgements}

Authors are highly grateful to Central University of Gujarat, Gandhinagar-382030, India, for financial and infrastructural support for this research work.

\section{References}

[1] Goering CE, Schwab AW, Daugherty J, Pryde H, Heakin J. Fuel properties of eleven vegetable oils. Trans ASAE 1982; 25:1472-83.

[2] Pryor RW, Hanna MA, Schinstock JL, Bashford L. Soybean oil fuel in a small diesel engine. Trans ASAE 1982; 26:333-8. 
[3] Demirbas A, Kara H. New options for conversion of vegetable oils to alternative fuels. Energy Sources 2006; 28:619-26.

[4] Backer LF, Jacobsen L, Olson JC. Farm-scale recovery and filtration characteristics of sunflower oil for use in diesel engines. J Am Oil Chem Soc 1983; 60:1558-60.

[5] Peterson CL, Auld DL, Korus RA. Winter rape oil fuel for diesel engines: recovery and utilization. J Am Oil Chem Soc $1983 ; 60: 1579-87$.

[6] Pryde EH. Vegetable oils as diesel fuels: overview. J Am Oil Chem Soc 1983; 60: 1557-8.

[7] Ryan TW, Dodge LG, Callahan TJ. The effects of vegetable oil properties on injection and combustion in two different diesel engines. J Am Oil Chem Soc 1984; 61:1610-9.

[8] Nitschke WR, Wilson CM. Rudolph Diesel, pioneer of the age of power. Norman, OK: The University of Oklahoma Press; 1965.

[9] Barnwal BK, Sharma MP. Prospects of biodiesel production from vegetable oils in India. Renew Sust Energy Rev 2005; 9:363-78.

[10] Vellguth G. Performance of vegetable oil and their monoesters as fuels for diesel engines. SAE 1983; 83:1358.

[11] Murugesan A, Umarani C, Subramanian R, Neunchezhain N. Biodiesel as an alternative fuel for diesel engines- A review. Renew Sust Energy Rev 2009; 13:653-62.

[12] Ergeneman M, Ozaktas T, Cig ^izog lu KB, Karaosmanog lu F, Arslan E. Effect of some Turkish vegetable oil-diesel fuel blends on exhaust emissions. Energy Sources 1997; 19: 879-85.

[13] Ma F, Hanna MA. Biodiesel production: a review. Bioresour Technol 1999; 70:1-15.

[14] Helwani Z, Othman MR, Aziz N, Fernando WJN, Kim J. Technologies for production of biodiesel focusing on green catalytic techniques: A Review. Fuel Process Technol 2009; 90:1502-14.

[15] Rakopoulos CD, Antonopoulos KA, Rakopoulos DC, Hountalas DT, Giakoumis EG. Comparative performance and emissions study of a direct injection diesel engine using blends of diesel fuel with vegetable oils or bio-diesels of various origins. Energy Convers Manage 2006; 47:3272-87.

[16] Rakopoulos DC, Rakapoulos CD, Papagiannakis RG, Kyritsis DC. Combustion heat release analysis of ethanol or n-butanol diesel fuel blends in heavy-duty diesel engine. Fuel 2011; 90:1855-67.

[17] Ali Y, Hanna MA. Alternative diesel fuels from vegetable oils. Bioresource Technol 1994; 50:153-63.

[18] Chang DYZ, Van Gerpen JH, Lee I, Johnson LA, Hammond EG, Marley SJ. Fuel properties and emissions of soybean oil esters as diesel fuel. J Am Oil Chem Soc 1996; 73:1549-55.

[19] Galan M, Bonet J, Sire R, Reneaume J, Plesu AE. From residual to useful oil: revalorization of glycerine from the biodiesel synthesis. Bioresour Technol 2009; 100:3775-8.

[20] Pagliaro M, Ciriminna R, Kimura H, Rossi M, Della Pina C. From glycerol to value-added products. Angew Chem Int Ed 2007; 46:4434-40.
[21] Singh P, Khurma J, Singh A. Coconut oil based hybrid fuels as an alternative fuel for diesel engines. Am J Environ Sci 2010; 6:69-75.

[22] Pryde EH. Vegetable oils as fuel alternatives-symposium overview. J Am Oil Chem Soc 1984; 61:1609-10.

[23] Knothe G, Jurgen K, Van GJ. The biodiesel handbook. J Am Oil Chem Soc Press: 2005; 245-58.

[24] Do LD, Singh V, Kibbey T, Gollahalli SR, Sabatini DA. Algae, canola, or palm oils-diesel microemulsion fuels: phase behaviors, viscosity and combustion properties. Int J Green Energy 2011; 8:748-67.

[25] Koh MY, Mohd Ghazi TI. A review of biodiesel production from Jatropha curcas L. Oil. Renew Sust Energy Rev 2011; $15: 2240-51$.

[26] Tat ME, Van Gerpen JH, Soylu S, Canakci M, Monyem A, Wormley S. The speed of sound and isentropic bulk modulus of biodiesel at $21^{\circ} \mathrm{C}$ from atmospheric pressure to $35 \mathrm{MPa}$. J Am Oil Chem Soc 2000; 77:285-9.

[27] Ryan TW, Dodge LG, Callahan TJ. The effects of vegetable oil properties on injection and combustion in two different diesel engines. J Am Oil Chem Soc 1984; 61: 1610-9.

[28] Alptekin E, Canakci M. Characterization of the key fuel properties of methyl ester-diesel fuel blends. Fuel 2009; $188: 75-80$

[29] Pratas MJ, Freitas S, Oliveira MB, Monteiro SC, Lima AS, Coutinho JAP. Densities and viscosities of fatty acid methyl and ethyl esters. J Chem Eng Data 2010; 55: 3983-90.

[30] Pratas MJ, Freitas S, Oliveira MB, Monteiro SC, Lima AS, Coutinho JAP. Densities and viscosities of minority fatty acid methyl and ethyl esters present in biodiesel. J Chem Eng Data $2011 ; 56: 2175-80$.

[31] Samuel VDF, Mariana BO, Antonio JQ, Maria JP, Alvaro SL, Joao APC. Measurement and prediction of biodiesel surface tensions. Energy Fuels 2011; 25:4811-7.

[32] Becker W. Solvent extraction of soybeans. J Am Oil Chem Soc 1978; 55:754-61.

[33] Tat ME, Gerpen JHV. The specific gravity of biodiesel and its blends with diesel fuel. J Am Oil Chem Soc 2000; 77:115-9.

[34] Singh M, Kumar A. Hydrophobic Interactions of Methylureas in Aqueous Solutions Estimated with Density, Molal Volume, Viscosity and Surface Tension from 293.15 to 303.15 K. J Sol Chem 2006; 35:567-82.

[35] Singh M. Survismeter type I and II for surface tension, viscosity measurements of liquids for academic, and research and development studies. J Biochem Biophys Methods 2006; 67:151-61.

[36] Singh M. A simple instrument for measuring surface tension and viscosity of liquids, J Intr Exp Techn 2005; 48:270-1.

[37] Singh M. Structural interactions of globular proteins-Bovine serum albumin, egg albumin and lysozyme in aqueous medium elucidated with molar volumes, viscosities, energy functions and IR spectra from 293.15 to 303.15 K. J Appl Poly Sci 2007; 103: 1420-9.

[38] Viswanath DS, Ghosh TK, Prasad DHL. Viscosity of Liquids Theory, Estimation, Experiment, and Data: Springer; 2007. 
[39] Azizian S, Hemmati M. Surface Tension of Binary Mixtures of Ethanol + Ethylene Glycol from 20 to $50{ }^{\circ} \mathrm{C}$. J Chem Eng Data 2003; 48:662-3.

[40] Vazquez G, Alvarez E, Navaza JM. Surface Tension of Alcohol Water + Water from 20 to $50{ }^{\circ} \mathrm{C}$. J Chem Eng Data 1995; 40:611-4.

[41] Witthayapanyanon A, Acosta EJ, Harwell JH, Sabatini DA. Formulation of ultra-low interfacial tension systems using extended surfactants. J Surfactants Deterg 2006; 9:331-9.
[42] Do LD, Witthayapanyanon A, Harwell JH, Sabatini DA. Environmentally friendly vegetable oil microemulsions using extended surfactants and linkers. J Surfactants Deterg $2009 ; 12: 91-9$.

[43] Koh MY, Mohd. Ghazi TI. A review of biodiesel production from Jatropha curcas L. Oil. Renew Sust Energy Rev 2011; 15:2240-51. 